\title{
O Debate dos Economistas sobre a Sustentabilidade - Uma Avaliação sob a Ótica da Análise do Processo Produtivo de Georgescu-Roegen
}

\author{
Charles C. Mueller
}

Professor Titular, Pesquisador Associado Sênior,

Departamento de Economia - UnB

\begin{abstract}
RESUMO
$O$ artigo avalia o debate que a economia do meio ambiente vem travando em torno do conceito de desenvolvimento sustentável, tendo por base contribuições de Nicholas Georgecu-Roegen. Este autor se notabilizou por ter trazido para a análise econômica o conceito de entropia, hoje peça fundamental da estrutura conceitual da economia ecológica. Entretanto, não é este o aspecto da obra de GeorgecuRoegen aqui focalizado. Ressaltam-se, ao invés, contribuições para a discussão derivadas de sua análise do processo produtivo. Procura-se mostrar, de forma especial, que a incorporação, pela economia do meio ambiente, da distinção, sugerida pelo autor, entre a categoria de capital natural de estoque e a de fundo de serviços ambientais básicos, forçaria as visões sobre a sustentabilidade a se confrontarem com aspectos fundamentais da inter-relação entre o sistema econômico e o meio ambiente, que hoje tendem a estar ocultos nas hipóteses simplificadoras da análise convencional da sustentabilidade.
\end{abstract}

\section{PALAVRAS-CHAVE}

sistema econômico e meio ambiente, sustentabilidade, categorias de capital, capital natural, estabilidade e resiliência, Georgescu-Roegen

ABSTRACT

Based on contributions from Nicholas Georgescu-Roegen, the paper evaluates the debate in economics regarding the concept of sustainable development. This author is renowned for having introduced in economic analysis the concept of entropy, today an important building block of ecological economics. However, this is not the aspect focused here. We emphasize, instead, the contribution to the discussion that can be derived from his analysis of the production process. We point out, especially, that if the analysis of the interaction between the economic system and the environment incorporates the distinction suggested by the author, between the category of stocks of inputs of natural capital and that of its funds of basic environmental services, the sustainability debate would be forced to confront central aspects that

tend to remain hidden by the simplifying assumptions of the conventional analyses of sustainability.

KEY WORDS

economic system and the environment, sustainability, categories of capital, natural capital, stability and resilience, Georgescu-Roegen

JEL Classification

Q01

EST. ECON., SÃO PAULO, V. 35, N. 4, P. 687-713, OUTUBRO-DEZEMBRO 2005 


\section{OS ECONOMISTAS E A NOÇÃO DE DESENVOLVIMENTO SUSTENTÁVEL}

O clima de opinião da década de 1970 caracterizou-se por um extremado pessimismo em relação aos impactos ambientais do funcionamento do sistema econômico. Esse pessimismo, entretanto, não perdurou, e um dos fatores para tal foram avaliações mais cuidadosas e menos emocionais da questão. Dentre estas, merece destaque a do relatório da Comissão Mundial do Meio Ambiente e Desenvolvimento (CMMD) das Nações Unidas. Deve-se a este a popularização da noção de desenvolvimento sustentável. Segundo o relatório da Comissão (CMMD, 1987, p. 43):

"Desenvolvimento sustentável é o desenvolvimento que garante o atendimento das necessidades do presente sem comprometer a capacidade das geraçôes futuras de atender suas necessidades. Engloba dois conceitoschave:

- o conceito de necessidades, em particular as necessidades básicas dos pobres de todo o mundo, aos quais se deve dar absoluta prioridade; $e$,

- o conceito de limitaçóes, impostas pelo estado da tecnologia e pela organização social, à capacidade do meio ambiente de assegurar sejam atendidas as necessidades presentes e futuras.”

O relatório sustenta que, a despeito de consideráveis obstáculos, o desenvolvimento sustentável ainda é possível. As limitações - não só as esboçadas na conceituação, como também as decorrentes do estado dos recursos ambientais do nosso globo e da capacidade da biosfera de absorver impactos da atividade humana dos nossos dias - seriam passíveis de superação, "abrindo caminho a nova era de crescimento econômico." (CMMD, 1987, p. 8). Mas reconhece a necessidade de um esforço global intenso e persistente para que isto ocorra.

A noção de desenvolvimento sustentável foi popularizada pelo relatório da CMMD, mas começou a ser usada, em vários sentidos, já no início da década de 1980. (Lélé, 1991, p. 610). Do ponto de vista das inter-relaçôes entre o sistema econômico e o meio ambiente, o enfoque inicial foi essencialmente biocêntrico - era a natureza que devia ser preservada. A Comissão, em contraste, focalizou principalmente o funcionamento do sistema econômico. Mas a economia é vista como dependendo fundamentalmente de recursos naturais fornecidos pelo ecossistema global, bem como da capacidade deste de suportar a agressão promovida pela humanidade e de assimilar os resíduos, a poluição resultantes dos processos de produção e de consumo. A questão central é: pode se sustentar o atual padrão de funcionamento do sistema econômico? 
Para a comissão, "A satisfação das necessidades humanas é o objetivo máximo do desenvolvimento... O desenvolvimento sustentável requer que as necessidades básicas de todos sejam atendidas e que sejam estendidas a todos a oportunidade de satisfazer suas aspiraçóes por uma vida melhor.” (CMMD, 1987, p. 43-4). E por 'todos', a Comissão se refere aos seres humanos - não só os da atual geração, como também os que virão em um futuro, que deve se estender por muito tempo. O foco central é o bem-estar presente e futuro da humanidade, mas é claro que este depende de um manejo adequado da natureza. Esta é a essência da sustentabilidade.

Entretanto, o que é, na verdade, o desenvolvimento sustentável? O que se deseja sustentar? Uma natureza intocada? Defender tal coisa seria totalmente irrealista. Como fazer isto e ao mesmo tempo assegurar a satisfação de aspirações e desejos humanos? Até que ponto, num prazo muito longo, se pode almejar o desenvolvimento sem que se esgotem recursos naturais básicos e sem que haja mudanças drásticas na atual estabilidade longe do equilíbrio do ecossistema global?

Este trabalho procura avaliar como os economistas vêm tratando estas questões, tendo por base contribuições de Nicholas Georgecu-Roegen. Este autor se notabilizou por ter trazido para a análise econômica o conceito de entropia. ${ }^{1}$ Conforme mostram, entre outros, Faber et al. (1998), o conceito de entropia é peça fundamental na formulação da estrutura conceitual da economia ecológica. A contribuição de Georgescu-Roegen permitiu ressaltar a essência entrópica do funcionamento da economia, abrindo caminho para análises construídas sobre base mais realista das inter-relações entre o sistema econômico e o meio ambiente, centrais para avaliações bem fundadas da sustentabilidade do desenvolvimento. Entretanto, não é este o aspecto da obra de Georgescu-Roegen aqui focalizado. O que se procurou fazer, ao invés, é ressaltar importantes contribuições para a discussão do desenvolvimento sustentável que podem ser derivadas da análise do autor acerca do processo produtivo. Isto porque análises do processo produtivo levam, não só à teoria neoclássica do capital, como ao conceito de substitutabilidade entre fatores de produção que, como veremos, está na essência da avaliação da sustentabilidade do desenvolvimento feitas pela corrente dominante da economia do meio ambiente.

A seção 2 esboça aspectos da análise do processo produtivo de Georgescu-Roegen, básicos para a nossa discussão; a seção 3 focaliza o enfoque otimista da sustentabilidade de Solow, que hoje prevalece na economia ambiental neoclássica; a seção 4 se apóia na análise de Georgescu-Roegen para melhor explicitar aspectos da substitutabilidade entre capital produzido e capital natural; a seção 5 emprega elementos da análise da seção

1 Ver Georgescu-Roegen (1971; mas também 1975, 1977 e 1986). Conforme ressalta Boulding (1980, p. 184), "O conceito de entropia teve impacto muito pequeno sobre a economia até o surgimento do notável livro de Nicholas Georgescu-Roegen, A Lei da Entropia e o Processo Econômico." 
anterior, bem como as hipóteses ambientais de correntes de pensamento da economia do meio ambiente para uma avaliação de visões otimista e pessimista de tais correntes; e a seção 6 apresenta comentários conclusivos.

\section{ELEMENTOS DA ANÁLISE DE GEORGESCU-ROEGEN ACERCA DO PRO- CESSO PRODUTIVO}

Os economistas consideram o funcionamento do sistema econômico focalizando dois processos básicos: o processo de produção e o de consumo. Para a microeconomia, a análise do processo de consumo é objeto da 'teoria do consumidor'. ${ }^{2}$ Esta evoluiu no tempo, num árduo esforço de formação e reconstrução que culminou na teoria ordinalista do consumidor, e que sobrevive até hoje. A formulação inicial da teoria do consumidor seguiu um caminho equivocado; os fundadores da economia neoclássica acreditavam que o consumidor demanda um dado bem guiado pela utilidade que espera derivar de seu consumo, e que essa utilidade é um atributo concreto, cardinalmente mensurável, do consumo do bem. Reconheceram que não havia como medir a utilidade do consumo, mas acreditavam que cedo ou tarde se descobriria uma maneira de realizar tal mensuração. Mas isto não aconteceu e a hipótese da mensurabilidade da utilidade acabou sendo abandonada quando um grupo de economistas construiu, com o emprego de rigoroso instrumental analítico, a teoria ordinalista do consumidor. Esta partiu da hipótese de que, para se conhecer o comportamento de um indivíduo em face do consumo, não é preciso medir utilidade. É necessário apenas supor que o consumidor ordena racional e consistentemente suas preferências em relação às possibilidades de consumo. Esta suposição está no âmago da atual teoria do consumidor.

A reconstrução analítica da teoria do consumidor contou com a participação de alguns dos melhores economistas da primeira metade do século passado, como, por exemplo, o Prêmio Nobel Paul Samuelson. (Simonsen, 1971, cap. 4). Dentre os que se destacaram nesse procedimento está a figura de Nicholas Georgescu-Roegen. As suas principais contribuições nesse campo estão no seu Analytical Economics, ${ }^{3}$ e a importância de sua participação é reconhecida, com efusivos elogios, por Samuelson no prefácio do livro.

Mas Georgescu-Roegen não se contentou apenas em participar da reconstrução da teoria do consumidor; avançando, procedeu a uma reavaliação do outro componente básico do sistema econômico - o processo de produção. $\mathrm{E}$ ao fazer isto acabou se voltando à análise das inter-relaçóes entre a economia e o meio ambiente.

2 Para uma boa cobertura da evolução da teoria do consumidor, ver Simonsen (1971, 1ª. Parte).

3 Ver Georgescu-Roegen (1967, Parte II). 
Já de início Georgescu-Roegen constatou a forma descuidada em que o processo de produção costuma ser tratado pela análise econômica dominante. ${ }^{4}$ Lamentou o fato de que os autores envolvidos na construção da teoria da produção não sentissem a "necessidade de levantar a mesma espécie de dívidas epistemológicas sobre a função de produção, que as que angustiaram os estudiosos do comportamento do consumidor." (Georgecu-Roegen, 1969, p. 498). Para o autor, isso provavelmente se deveu ao fato de que a produção de mercadorias emana de processos físico-químicos, que seguem as leis da natureza, e que são passíveis de mensuração com certa precisão. Essa mensurabilidade parecia assegurar à teoria da produção uma maior confiabilidade que a da teoria do consumidor, não obstante a semelhança formal que existe entre o instrumental analítico das duas teorias.

A reconstrução de Georgescu-Roegen acerca da teoria da produção - esboçada adiante partiu de cuidadosa apreciação crítica dos princípios, das hipóteses e dos fundamentos lógicos da abordagem convencional. Ela permitiu ao autor identificar algumas deficiências da abordagem convencional, que tomou o cuidado de evitar em sua reconstrução. Estabeleceu, assim, um conjunto minuciosamente ponderado de hipóteses, que serviram de base para uma análise rigorosa do funcionamento do processo produtivo.

Mas a abordagem de Georgescu-Roegen não obteve o reconhecimento da parte do establishment da análise econômica convencional. Uma das razões para isto se deve provavelmente ao fato de que a sua reconstrução acabou lançando fortes dúvidas sobre a pertinência de alguns dos instrumentos de análise e de determinadas formas de aplicação de uso corrente na teoria da produção dominante. Assim, esta última sobreviveu quase a mesma até os nossos dias; a teoria econômica convencional simplesmente continua a focalizar o processo produtivo de forma equivocada, mas convenientemente simples. Além disso, ao ignorar aspectos essenciais desse processo, a análise convencional gerou visóes distorcidas e inconsistentes acerca da sustentabilidade do funcionamento do sistema econômico contemporâneo.

\section{Aspectos Básicos da Análise de Georgescu-Roegen Acerca do Processo Produtivo ${ }^{5}$}

Como se sabe, a teoria econômica apóia a sua análise do processo produtivo no conceito de função de produção. Pode-se definir função de produção como uma lista de to-

4 Antes de Georgescu-Roegen, Joan Robinson (1953-54) já havia criticado acerbamente a maneira descuidada como a teoria neoclássica trata a função de produção. Essa autora responsabiliza, inclusive, a análise convencional do processo produtivo por difundir, de geração a geração de economistas, hábitos descuidados (sloppy) de pensamento (p. 81).

5 Ver, de forma especial, Georgescu-Roegen (1969), e o capítulo IX da obra máxima do autor, The Entropy Law and the Economic Process. (Georgescu-Roegen, 1971). 
dos os processos ótimos pelos quais uma dada quantidade de um produto pode ser obtida de cada combinação possível de fatores. Via de regra, muitas combinaçõos de fatores permitem chegar a essa quantidade de produção, mas só tem interesse econômico processos ótimos, ou seja, processos que levem à produção máxima possível de se obter de uma determinada combinação de fatores de produção.

A falta de espaço nos obriga a efetuar descrição breve da abordagem de Georgescu-Roegen, ressaltando apenas aspectos essenciais para a nossa discussão. $\mathrm{O}$ autor começa delimitando minuciosamente o significado de processo parcial e mostrando a forma epistemologicamente correta de estudar o seu funcionamento. Argumenta que quando descrevemos uma função de produção estamos implicitamente supondo o processo produtivo em estado estacionário - no sentido de que seja lá o que o processo execute, isso possa ser sempre repetido. ${ }^{6}$ Ou seja, devemos supor que, uma vez terminado um ciclo de execução de produção, os elementos básicos do processo - que compóem a sua estrutura - se mantêm inalterados, permitindo com que, no futuro, o processo possa ser repetido da mesma maneira. Ao realizar a produção, o processo também se autoreproduz.

A necessidade da hipótese de estado estacionário decorre do fato de que, sem ela, ao final de cada ciclo de realização de uma determinada produção teríamos não apenas produtos e resíduos, mas também a estrutura do processo produtivo transformada pelo desgaste de máquinas e pelo cansaço de trabalhadores.

Essa hipótese fundamental da abordagem de Georgescu-Roegen acerca do processo de produção não nos permite concluir, entretanto, que a variável 'tempo' não tem nenhum papel na análise. O processo de produção tem uma dimensão temporal, que decorre do fato de que leva tempo para que a produção se efetive. Esta ocorre ao longo de um intervalo de tempo $[0, \mathrm{~T}]$, sendo o momento 0 o instante em que o processo começa a ser executado, e T o instante em que a produção se completa; o processo não opera antes de 0 , e nem depois de T. Além disso - à exceção da produção manufatureira em linha - os fatores e insumos não penetram a fronteira do processo todos juntos e nem atuam continuamente ao longo da realização da produção. E, mesmo em economias avançadas, há muitos casos de produção que não pode ocorrer em linha - exemplos importantes estão na agricultura, na produção por encomenda (inclusive de equipamentos sofisticados), na construção civil (via de regra). Em casos como estes, é fundamental estabelecer nitidamente o padrão temporal da participação dos insumos na produção.

6 Georgescu-Roegen (1971, p. 229) conceitua um sistema estacionário como um sistema que, seja lá o que ele faça, possa ser repetido identicamente vez após vez. Para exemplificar um sistema em estado estacionário, o autor cita o modelo de reprodução simples de Marx. 
Diferentemente do que acontece com a teoria da produção convencional, GeorgescuRoegen caracteriza com especial cuidado os elementos básicos do processo produtivo: os fatores de produção. Em essência, estes se apresentam em duas categorias:

- A dos fatores de fundo, os agentes do processo, que compóem a sua base material. Eles prestam serviços na transformação de insumos em produtos.

- A dos fatores de fluxo: a energia, os materiais, os componentes que o processo produtivo transforma em produto.

Observando o funcionamento do processo, vemos os fatores de fundo atuar sobre os fatores de fluxo, transformando-os em produtos. As coordenadas de fundo do processo produtivo podem ser classificadas segundo sua natureza ou o seu papel no processo. Com base na tipologia introduzida pelos economistas clássicos, Georgescu-Roegen sugere as seguintes categorias:

$\mathbf{L}=$ Terra ricardiana (espaço físico);

$\mathbf{K}=$ Capital (máquinas, equipamentos, ferramentas, construções);

$\mathbf{H}=$ Força de trabalho.

Um aspecto fundamental - que a teoria da produção convencional não explicita - está no fato de que no processo de produção nenhum dos fatores de fundo se incorpora, fisicamente, ao produto. Todos eles atuam prestando serviços para a geração de produtos. A terra ricardiana - o espaço físico em que se realiza a produção - embora inerte, presta serviços fundamentais. O fator de fundo capital - as máquinas e equipamentos, as construções - atuam sobre fatores de fluxo, transformando-os em produtos; e é evidente que não se incorporam a estes. ${ }^{7} \mathrm{O}$ mesmo ocorre com o fator força de trabalho; o papel do trabalhador no processo produtivo é o de atuar na transformação de insumos em produtos; nenhuma parte dele deve se incorporar à produção. ${ }^{8}$

Quanto aos fatores de fluxo, Georgescu-Roegen sugere as seguintes categorias:

$\mathbf{R}=$ Insumos da natureza;

I = Insumos correntes (produzidos);

$\mathbf{M}=$ Manutenção.

7 Conforme ressalta Georgescu-Roegen (1971), a agulha de um alfaiate é implemento importante na produção de uma calça, mas ela não se incorpora à calça. Se o consumidor encontra uma agulha enfiada na calça que compra, este é um incidente lamentável.

8 Quando isto acontece, temos, outra vez, um incidente lamentável, como bem ilustra a situação em que um fio de cabelo do cozinheiro é encontrado no prato de sopa do cliente de um restaurante. 
Os fatores de fluxo $\mathbf{R}$ compreendem os insumos fornecidos pela natureza: a energia solar, as chuvas, o petróleo e o carvão no subsolo, os nutrientes contidos nos solos agrícolas $^{9}$ etc. Os fatores de fluxo I compreendem, por sua vez, insumos materiais transformados pelo processo produtivo, que se originam de outros processos de produção. E a categoria dos insumos de manutenção, $\mathbf{M}$, compreende os fluxos de insumos necessários para deixar os equipamentos usados na produção em bom estado de funcionamento; tem, basicamente, a ver com o fator de fundo $\mathbf{K}$.

Pode parecer estranha a não inclusão do fluxo de insumos associados à 'manutenção' do fundo da força de trabalho, que também se desgasta (se cansa) ao participar da produção. Georgescu-Roegen reconhece que o trabalhador requer uma determinada quantidade de meios para a sua própria subsistência, e a de sua família. Para que a sua capacidade de produzir permaneça intacta, se requer que parte do salário (ou todo ele) custeie a recuperação dessa capacidade, em boa medida, no âmbito do lar. Como é difícil determinar de forma minimamente precisa os elementos do fluxo de manutenção da força de trabalho, Georgescu-Roegen não inclui no processo a 'manutenção' da força de trabalho. Presume que ela seja custeada pelo salário do trabalhador e que ocorra fora do local da produção.

Os fatores de fundo e os de fluxo são os agentes e insumos do processo produtivo. Eles penetram a sua fronteira ao longo do intervalo de tempo $[0, \mathrm{~T}]$ em que se realiza a produção. E, o que deixa a fronteira do processo em T? Sem dúvida, isto acontece com os fatores de fundo - os agentes do processo. Mas, adicionalmente, deixam o processo dois outros fluxos: o de produtos, Q; e, o de resíduos, de rejeitos, de poluição, W.

A teoria convencional da produção considera que, ao término do processo, apenas $\mathbf{Q}$ deixa a sua fronteira. Ignora, assim, o fluxo que invariavelmente também emana do processo produtivo - e sem exceções: o fluxo de resíduos, de rejeitos, de poluição, W. Se em alguns casos há poucos resíduos, em muitos outros eles podem ser consideráveis. Mas a geração de resíduos pelo sistema econômico está no âmago da questão ambiental dos nossos dias. Eles são conseqüência do funcionamento de duas leis da natureza: a lei da conservação da matéria e da energia, e a lei da entropia. E estas não podem ser revogadas, por mais avançada que sejam as nossas tecnologias. Conforme ressalta Georgescu-Roegen, é um absurdo, pois, ignorar esse fluxo fundamental.

Os fatores de fundo são os agentes do processo produtivo. Entretanto, ao longo da operação do processo, a intensidade do uso dos serviços desses agentes na transformação dos fatores de fluxo em produto varia de acordo com as necessidades de cada etapa

9 O solo agrícola é, simultaneamente, fator de fundo terra ricardiana - o espaço físico que recebe as plantas e permite que captem energia solar para se desenvolverem; e é repositório de nutrientes tornados disponíveis às plantas. Esses nutrientes se constituem em fatores de fluxo. 
do processo. Há momentos em que um determinado fator de fundo permanece ocioso, mas há outros em que é intensamente utilizado. Ao produzir um móvel, por exemplo, um marceneiro usa sua serra em alguns momentos, mas em outros ela fica ociosa; e o mesmo acontece com outras ferramentas necessárias à produção. Há, assim, um padrão temporal dos serviços dos fatores de fundo prestados à produção, que precisa ser considerado.

Com base nesse argumentos, Georgescu-Roegen mostra que o correto é representar a função de produção - um catálogo de todos os processos parciais ótimos para a produção de um dado produto - por uma fórmula do seguinte tipo:

$$
\mathrm{Q}(\mathrm{t})=F\{\mathrm{~L}(\mathrm{t}), \mathrm{K}(\mathrm{t}), \mathrm{H}(\mathrm{t}) ; \mathrm{R}(\mathrm{t}), \mathrm{I}(\mathrm{t}), \mathrm{M}(\mathrm{t}), \mathrm{W}(\mathrm{t})\}
$$

Trata-se de relação que, no jargão matemático, recebe o nome de funcional, ou seja, uma função que relaciona a variável dependente (a produção) a outras funções; note-se que todas as variáveis contidas $\operatorname{em~} \mathrm{F}\{\bullet\}$ são função do tempo.

A análise de Georgescu-Roegen contrasta com a representação da teoria da produção convencional, difundida nos livros de textos. O problema é que a representação convencional é feita sem uma caracterização adequada do processo analisado. Conforme mostra Georgescu-Roegen (1969, p. 499), nos primórdios do desenvolvimento da teoria da produção os economistas ainda se preocupavam em analisar a natureza dos fatores de produção, mas quando se inventou o termo 'insumo' esse tipo de discussão ficou de lado e passou-se a tratar todos os fatores de produção como de natureza semelhante.

O autor enfatiza a diferença entre a sua representação - conceitualmente bem mais rigorosa - e a da teoria da produção convencional. Demonstra que a sua representação só se aproxima da comumente adotada pela análise convencional em um caso especial: o da produção manufatureira em linha; ou seja, nos casos em que é possível arranjar todos os fatores de fundo em linha, fazendo-os prestar serviços contínua e ininterruptamente na transformação dos fatores de fluxo. É o que se observa nas linhas de montagem, comuns na indústria automobilística. A produção agrícola, entretanto, não se enquadra nesse molde, e nem os diversos tipos de produção por encomenda, na qual uma unidade de produto é diferente de outras produzidas pela empresa.

\section{Estoques e Fundos: Uma Diferenciação Fundamental}

São conhecidas as diferenças analíticas entre estoques e fluxos. Um estoque é uma quantidade de alguma coisa que se acumulou; refere-se a um dado ponto do tempo. $\mathrm{E}$ 
esse estoque é alterado por fluxos de entrada e de saída dos elementos que o compõem. Ao longo do tempo, um estoque pode aumentar ou sofrer reduções, dependendo das magnitudes dos fluxos de entradas e de saídas dos componentes do estoque.

Isso pode parecer elementar. Mas, tendo em vista a distinção acima entre fatores de fundo e fatores de fluxo, quando dizemos, por exemplo, que o estoque do fundo de capital fixo de um país aumentou entre dois anos, o que isto significa? Será válido, estritamente falando, caracterizar esse capital, como 'estoque'? Tratando deste ponto, Georgescu-Roegen (1971, p. 225-28) reconhece que uma unidade do equipamento de uma empresa é um estoque, e que o mesmo pode ser dito a respeito da totalidade das máquinas, equipamentos e construções de um país em uma determinada data, computada pelo seu sistema de contas patrimoniais. Expresso em termos monetários, este é o estoque de capital fixo do país. Entretanto, o sentido do termo 'estoque' nesses dois casos é totalmente diferente do empregado quando nos referimos ao estoque de uma matéria-prima usada por uma empresa; ou, ainda, tendo em vista as contas nacionais de um país, quando nos referimos à variação de estoques - um item da conta investimento - ao longo de um ano. Como diferem esses dois sentidos da expressão 'estoque'?

A maioria dos economistas trata os dois componentes da conta capital como partes de uma única coisa - o estoque de capital. Mas isto não é estritamente correto; a natureza desses dois componentes é muito diferente. O que distingue os dois sentidos da expressão 'estoque', é o fato de que, enquanto um estoque de carvão é fisicamente 'consumido' quando de seu uso na alimentação da fornalha de uma máquina a vapor, uma máquina em uso numa fábrica representa, por assim dizer, um estoque dos serviços que ela pode prestar à produção. Observe-se, entretanto, que - sempre supondo fluxos de manutenção adequados - a prestação desses serviços pela máquina não a consome, pelo menos não da mesma forma como o que acontece com o uso do carvão. Para diferenciar os estoques de matérias-primas e componentes em um processo produtivo dos estoques de máquinas e equipamentos usados no processo foi que Georgescu-Roegen (1969, p. 512), inspirado no fisiocrata Jean Baptiste Say, denominou a estes últimos, fundos de serviços.

Elaborando a distinção, imaginemos o estoque de matéria-prima que uma empresa emprega na sua produção, que se acumule ao longo de um ano; isso ocorre pela adição concreta de quantidades físicas da matéria-prima. No ano, entra uma quantidade da matéria-prima, que excede às retiradas do estoque para uso. No caso do estoque denominado de 'fundo' isto não ocorre. Conforme ressalta Georgescu-Roegen (1971, p. 227), "uma máquina não é criada pela acumulação dos serviços que ela fornece como um fundo (...). Serviços não podem ser acumulados de forma semelhante aos dólares em uma conta de poupança, ou aos selos em uma coleção.” 
Além disso, a existência de um dado fundo de serviços torna disponíveis serviços ao processo de transformação de insumos em produtos. E, em um dado período, só há duas alternativas para esses serviços: ou eles são usados ou, como ocorre com parte do capital fixo de uma economia em recessão, são desperdiçados. Não dá para 'guardar' para futuro uso os serviços não utilizados; se no período seguinte a demanda se aquece e a capacidade produtiva não for suficiente para atendê-la, não é possível usar, em adição à capacidade produtiva existente naquele momento, a parte do potencial produtivo desperdiçado durante a fase recessiva. Essa distinção entre estoque e fundo tem importantes implicaçốes para a discussão, adiante, da sustentabilidade.

A teoria da produção convencional esconde, pois, aspectos essenciais do processo produtivo. Suas elaborações são, entretanto, convenientes, pois permitem o uso do cálculo matemático para derivar uma série de proposiçóes sobre o processo produtivo, o que não ocorre com a funcional de Georgescu-Roegen. Na verdade, a adoção da abordagem mais completa e rigorosa desse autor torna sem sentido muitas das aplicaçôes empíricas, como, por exemplo, as estimações de funções de produção. Para GeorgescuRoegen (1971, p. 245), "os teoremas que adornam a teoria marginalista da determinação de preços são, em última instância, ornamentos analíticos enganosos”; o único papel de funções de produção deveria ser o de determinar quais os fatores de produção que participam de um dado processo produtivo e em que quantidades, para, com isto, então compor custos de produção.

\section{A ABORDAGEM FORTEMENTE ECONOCÊNTRICA DA SUSTENTABILIDA- DE DE ROBERT SOLOW}

A partir do início da década de 1970, o Prêmio Nobel Robert Solow, um expoente da análise econômica convencional, com importantes contribuições à teoria do capital, do crescimento econômico e, mais recentemente, dos recursos naturais, vem discutindo o conceito de sustentabilidade do ponto de vista da análise econômica. Para Solow (1993, p. 163), “... se 'sustentabilidade’ tiver que ser algo além de um 'slogan’ ou manifestação de emoção, a expressão deve ser uma injunção para a preservação da capacidade produtiva por todo o tempo." Na verdade, essa injunção também está contida na definição da CMMD. O autor reconhece que esta definição - como também a sua - é vaga, mas considera que este é um atributo positivo. ${ }^{10}$

Ao explicar por que é contra realizar esforços para aumentar a precisão do conceito de desenvolvimento sustentável, Solow parte da premissa de um forte compromisso ético da humanidade com as gerações futuras. Aceitando esta premissa, o que o conceito de

10 A discussão aqui se apóia em Solow (1993), e em palestra do autor aos ambientalistas do Marine Policy Center do Woods Hole Oceanographic Institution de Massachussetts, em 1991. 
sustentabilidade deve nos mandar fazer é evitar executar, no presente, ações que tenham efeitos detrimentosos sobre os nossos descendentes - não apenas os mais diretos, mas também os que virão em um futuro mais distante. Argumenta que uma conceituação mais precisa de desenvolvimento sustentável talvez nos obrigue a fazer o impossível - como, por exemplo, legar aos nossos descendentes uma natureza intocada, um mundo exatamente igual ao que recebemos dos nossos antepassados. Isto, obviamente, não é possível; e, como ninguém pode ser moralmente obrigado a fazer o que não é possível, uma conceituação de sustentabilidade assentada em tal exigência nos desobrigaria a atuar para implementá-la na prática. No máximo, portanto, o que podemos exigir de nós mesmos é que atuemos visando à sustentabilidade conceituada de outra forma - a de legar às geraçóes futuras a possibilidade de terem níveis de bem-estar pelo menos iguais aos nossos hoje. O desenvolvimento sustentável deve, pois, ser encarado como um mandamento para que o nosso atual padrão de vida não seja conseguido à custa do empobrecimento das geraçôes futuras.

Solow argumenta que para dar maior precisão ao conceito de desenvolvimento sustentável seria necessário conhecermos com alguma precisão os gostos e preferências - elementos fundamentais para se dizer algo sobre níveis de bem-estar - das gerações futuras, mesmo aquelas que virão daqui a muito tempo (digamos, daqui a um século). Além disso, teremos que ter uma idéia mais ou menos segura a respeito das opçóes tecnológicas que serão criadas ao longo de um horizonte temporal muito extenso. Como não é possível antecipar, com um mínimo de precisão, esses elementos, o conceito de desenvolvimento sustentável precisa permanecer vago.

O autor reconhece, entretanto, a necessidade de restringirmos os impactos ambientais que produzimos para não inviabilizarmos a possibilidade das gerações futuras de usufruir níveis de bem-estar pelo menos iguais aos nossos. Enfatiza, entretanto, que ao avaliarmos essa restrição não devemos considerar apenas os recursos naturais que usamos e os que deixamos para o futuro; e o tipo de meio ambiente natural que existe agora e como este ficará; mas também aquilo que construímos com a contribuição de recursos ambientais: as máquinas e as edificações que acumulamos em nossas economias. Devemos também considerar o desenvolvimento tecnológico gerado a partir do conhecimento que se acumula.

É óbvio que os níveis de bem-estar social são afetados tanto pelo estado da natureza como pelos artefatos que acumulamos com o nosso esforço e a nossa engenhosidade. Aceitando isto, temos que ter em vista também o fato de que é possível haver substituição entre essas duas categorias de determinantes de bem-estar: os oriundos da natureza e os resultantes do esforço humano. Para Solow, em princípio, um mesmo nível de bem-estar pode ser obtido tanto com elevada contribuição da natureza e pouca da acumulação de artefatos humanos como com menos contribuição da natureza e maior par- 
ticipação de artefatos humanos. Assim, se ao longo do tempo houver uma redução do cabedal de recursos e atributos da natureza, isto não significa que o nível de bem-estar social estará se reduzindo, pois podem ter surgido no seu lugar frutos do esforço e da engenhosidade humanos em quantidades que compensem tal redução.

Na visão de Solow, portanto, a substitutabilidade é um atributo básico para que possamos determinar se o desenvolvimento é sustentável. Essa substitutabilidade pode se dar no âmbito do consumo, por exemplo, entre uma paisagem prístina e um ambiente construído que cause satisfação aos que dele têm acesso; e no âmbito da produção, quando um fator de produção construído substitui um atributo da natureza na produção. Existindo amplas substitutabilidades deste tipo, o atingimento do desenvolvimento sustentável - na conceituação de Solow -, deixa de ser impossível. O autor insiste, além disto, que tenhamos em conta as possibilidades que se abrem com o desenvolvimento tecnológico. A substitutabilidade e o desenvolvimento tecnológico são, assim, elementos básicos da sustentabilidade, e é fundamental que se adotem estratégias e políticas que maximizem o potencial de atuação destes.

Na verdade, essa visão de Solow (1991; 1993) é uma versão mais elaborada e atualizada da mensagem que há mais de 30 anos o autor passou a economistas, então em dúvida sobre a sustentabilidade do padrão contemporâneo de crescimento da economia mundial. Na sua aula magna de 1973 ao congresso da American Economic Association o autor delineou os elementos de sua argumentação. Segundo ele, então, se admitirmos que é relativamente fácil substituir, nos processos econômicos, recursos ambientais pelos fatores de produção 'trabalho' e, de forma especial, 'capital', e se acreditarmos que, com o crescimento econômico, virá o progresso técnico facilitador da poupança e/ou da substituição de recursos naturais, não há razão para preocupação. Nessas circunstâncias, se ao longo de uma contínua ampliação da escala da economia mundial houver a exaustão de um recurso natural, isto será "apenas um evento, e não uma catástrofe." A substitutabilidade e o progresso técnico garantem que "se o futuro for semelhante ao passado, por muito tempo ainda haverá consideráveis reduções nos requerimentos de recursos naturais por unidade de produto." (Solow, 1974, p. 10-11).

Como veremos, a substitutabilidade e o progresso técnico assumiram importância no debate mais recente no entorno dos requisitos econômicos da sustentabilidade. 


\section{O CAPITAL PRODUZIDO, O CAPITAL NATURAL E O DESENVOLVIMEN- TO SUSTENTÁVEL}

\section{A Sustentabilidade e as Diferentes Categorias de Capital}

A substitutabilidade entre fatores de produção é nossa velha conhecida. Há muito os economistas tratam, por exemplo, da substituição da mão-de-obra pelo capital em economias de mercado em que há um encarecimento relativo do fator de produção trabalho. Quando isto acontece, se mercados funcionam bem, haverá a substituição do trabalho pelo capital. A abordagem de Solow acerca da sustentabilidade conduz a considerações análogas, mas envolvendo a substituição daquilo que acabou recebendo a denominação de 'capital natural' - grosso modo, recursos ambientais - por 'capital produzido' - máquinas, construçôes, infra-estrutura etc.

Para Solow (1993), do ponto de vista da análise econômica, o desenvolvimento sustentável compreende o fluxo máximo de produto/renda que pode ser gerado a partir de um estoque de capital em expansão, obedecida a exigência da sua conservação. Essa exigência tem um papel fundamental; se a atual geração deixar para as geraçôes futuras um estoque de capital que não seja menor que o existente no presente, nossos descendentes terão condições de usar esse capital para gerar, pelo menos, o mesmo nível de bem-estar que usufruímos hoje. E também se aplica aos nossos descendentes a injunção da conservação do capital.

Como, dentre o que se deve conservar assumem destaque elementos da natureza, essa conceituação de desenvolvimento sustentável requer uma definição mais abrangente de capital que a comumente empregada pela análise econômica. Recentemente, foram surgindo referências a diferentes categorias de capital, ${ }^{11}$ como:

- O capital produzido (Kp), compreendendo o estoque de máquinas, de construções, de infra-estrutura que uma sociedade dispõe em um determinando momento. É o capital físico gerado e acumulado pelo sistema econômico. Trata-se da categoria enfatizada, por exemplo, pelos modelos neoclássicos de crescimento.

- O capital bumano $(\mathbf{K h})$, que envolve a capacitação e as habilidades para produzir da força de trabalho da sociedade em um dado momento. Para aumentar o seu capital humano a sociedade investe em educação, em treinamento, em capacitação. Este componente tem recebido atenção especial recentemente.

11 Reconhecemos que o tratamento que se popularizou dessas diferentes categorias de capital também se constitui em exemplo do que Joan Robinson denominou de "hábitos displicentes de pensamento". 
- O capital social (Ks), que inclui, em essência, a estrutura institucional da sociedade em um dado momento do tempo. Reconhece-se que a eficácia dessa base institucional tem um papel central no desenvolvimento de uma economia.

- O capital natural (Kn) é um item complexo e que, como veremos, vem sendo tratado de forma bastante descuidada. Inclui tanto os estoques de recursos energéticos e de outros recursos naturais aos quais se têm acesso em um dado momento, como os estados biofísicos existentes no meio ambiente (as condições climáticas, as características de ecossistemas, a capacidade de regeneração de sistemas naturais etc.) nesse mesmo momento.

Vimos que, para Solow, à medida que a economia se expande, o capital natural, Kn, pode ser substituído por outras formas de capital, notadamente o capital produzido, $\mathrm{Kp}$, e o capital humano, Kh. Para este autor e seus seguidores, o que se quer conservar para que haja sustentabilidade é o estoque de capital total, $\mathrm{K}$, da economia, e não apenas $\mathbf{K n}$, o capital natural. K compreende o agregado de todas as categorias de capital. Supondo a mensurabilidade dessas categorias em unidades monetárias, teríamos:

$$
\mathbf{K}=\mathbf{K p}+\mathbf{K n}+\mathbf{K h}+\mathbf{K s}
$$

Embora essa conceituação do capital tenha certo apelo intuitivo, até recentemente a análise econômica focalizava quase exclusivamente $\mathbf{K p}$, o capital produzido. Uma das razóes para isto está na relativa facilidade de se computar em termos monetários a magnitude dessa categoria de capital. Para as demais categorias, as dificuldades de mensuração em termos monetários são bem maiores. Na discussão que se segue fugimos das complicações de mensuração e agregação; apenas para argumentar, fazemos a hipótese de que existem formas aceitáveis de mensurar em termos monetários todos os componentes de $\mathbf{K} .^{12}$

Um exame dos modelos neoclássicos de crescimento revela que, para estes, o que vale é, juntamente com a expansão da força de trabalho e o progresso técnico, a acumulação do capital produzido. Para esses modelos, $\mathrm{K}=\mathbf{K}$; e eles tendem a mostrar que basta que o capital produzido se acumule a uma taxa adequada para que um crescimento continuado - portanto sustentável na conceituação de Solow - ocorra. Sabemos, porém, que, por necessidade, a economia do meio ambiente - mesmo na sua variante derivada diretamente da análise econômica convencional - focaliza o funcionamento do sistema econômico inserido no meio ambiente, do qual retira recursos naturais funda-

12 Não resta dúvida, entretanto, que esta é uma hipótese extremamente forte. Como revela a controvérsia das duas Cambridges dos anos 60 - até hoje não inteiramente resolvida - há reservas teóricas a respeito da validade de se representar em termos monetários até a Kp, o capital produzido. Para uma avaliação recente da controvérsia, ver Cohen e Harcourt (2003). 
mentais, e no qual deposita rejeitos dos processos econômicos; seus modelos não podem, pois, ignorar os recursos e serviços fornecidos pelo capital natural. E são forçados a considerar os efeitos ambientais do crescimento.

\section{Substitutabilidade, Otimismo e Pessimismo em Relação à Sustentabilidade}

Do ponto de vista econômico, a sustentabilidade envolve algum grau de conservação do capital natural, pois este é finito e, de muitas formas, frágil. Há muito tempo os ecologistas vêm afirmando que a preservação das condiçôes de bem-estar das gerações futuras depende, de forma crucial, de tal conservação. Insistem que um uso inadequado do capital natural pode impedir que o desenvolvimento seja sustentável. A economia do meio ambiente aceita isto até certo ponto. Na verdade, abordagens diferentes desse ramo da análise econômica apresentam divergências no que tange à importância efetiva do capital natural para o desenvolvimento sustentável. Dois conceitos ilustram tais divergências: o conceito de sustentabilidade fraca (Sfra) e o de sustentabilidade forte (Sfor). A diferença entre os dois tem a ver justamente com suas hipóteses sobre o grau de substitutabilidade entre diferentes tipos de capital.

Para simplificar a discussão, focalizamos apenas as categorias de capital mais diretamente relevantes para a economia do meio ambiente: a do capital produzido, Kp; e a do capital natural, Kn. A idéia básica é que o crescimento que acompanha o desenvolvimento sustentável requer ambos esses tipos de capital. ${ }^{13}$ Ou seja,

\section{Crescimento do produto $=\mathrm{F}(\Delta \mathrm{K} / \Delta \mathrm{t})=\mathrm{F}\{(\Delta \mathrm{K} \mathrm{p} / \Delta \mathrm{t}) ;(\Delta \mathrm{Kn} / \Delta \mathrm{t})\}$}

Para a visão da sustentabilidade fraca (Sfra), K tem como crescer de forma quase ilimitada, basicamente porque considera que Kp e Kn podem, com facilidade, substituir um ao outro. Assim, se o capital natural se tornar escasso ao longo do processo de expansão econômica, o preço relativo de seus serviços aumentará. Tornando-se mais caros, ocorrerá a substituição de Kn pelo capital produzido. Assim, mesmo que o crescimento econômico reduza significativamente o estoque de $\mathbf{K n}$ da sociedade, o crescimento poderá continuar a ocorrer com $\mathrm{Kp}$ tomando o lugar de Kn. Para que isto ocorra os mercados precisam funcionar bem, sinalizando a necessidade da substituição. E a substituição se tornará mais fácil se houver desenvolvimento tecnológico. Essa visão tende a prevalecer na corrente da economia do meio ambiente que emanou diretamente da análise econômica convencional: a da economia ambiental neoclássica.

13 Para uma argumentação nessa mesma linha, embora enviesada no sentido da economia ambiental neoclássica, ver Pearce e Turner (1990, cap. 3). 
Já a visão da sustentabilidade forte (Sfor) é bem menos otimista em relação ao desenvolvimento sustentável, pois considera limitada a substitutabilidade entre $\mathbf{K p}$ e $\mathbf{K n}$. Aceita que, até certo ponto, esta existe, mas considera que se o crescimento for acompanhado de escassez relativa cada vez maior de capital natural ele poderá ser inviabilizado. Isso aconteceria porque acabaria prevalecendo relação de complementaridade entre essas duas categorias de capital. Se houver substancial complementaridade entre elas, para que um montante adicional de produto real seja gerado na economia serão necessárias mais de ambas as categorias de capital. Uma expansão contínua do produto real da economia requererá, assim, a conservação do capital natural; e se Kn se tornar extremamente escasso, o produto da economia poderá cessar de crescer. A visão da Sfor tende a prevalecer nas abordagens da economia ecológica.

Um exame do emprego que se faz dessas duas visóes no debate sobre a sustentabilidade da economia contemporânea, entretanto, revela que tanto os que defendem uma como os que se valem da outra tendem a fazê-lo de forma bastante solta. Os debates a esse respeito usualmente se valem mais de elevadas doses de fé do que de argumentos apoiados em sólida base conceitual. De forma especial, esses argumentos se assentam em concepções simplificadas e distorcidas de elemento central na promoção do crescimento econômico - a acumulação de 'capital'. Para as duas visões cada categoria de capital considerada (capital produzido, capital natural) compreende um conjunto de elementos de caráter semelhante. Como vimos, a diferença nas duas concepções de sustentabilidade está na hipótese de maior ou menor substitutabilidade entre as categorias Kp e Kn no âmbito do processo produtivo, mas a categoria $\mathrm{Kp}$, em si, é considerada de natureza semelhante, o mesmo ocorrendo com a categoria Kn. Fica, pois, difícil aos que defendem cada visão trazer ao debate argumentos mais que vagos.

A situação muda, entretanto, se especificarmos melhor a natureza de Kp e Kn, Fazendo isto, ampliamos a base para a discussão da sustentabilidade. Começamos com $\mathbf{K} \mathbf{p}, \mathbf{o}$ capital produzido e acumulado pelo sistema econômico. Embora Kp seja usualmente tratado como categoria uniforme, ela compreende elementos que deveriam ser tratados de forma distinta. Isto se torna visível se considerarmos como ocorre, na prática, a sua mensuração.

Em termos agregados, nos países em que o sistema de contas nacionais faz contabilidade patrimonial, o capital de uma economia em um dado momento do tempo é tratado como um estoque; mas esse estoque compreende dois conjuntos de elementos de natureza essencialmente distinta: o da totalidade das máquinas, equipamentos, construçôes da economia; e o do montante dos estoques - dos inventários - de mercadorias nas mãos das empresas (matérias-primas, produtos intermediários e bens de consumo ou de capital produzidos, mas ainda não adquiridos por usuários finais). Semelhantemente, o sistema de contas nacionais mede separadamente, na conta investimento, a 
formação bruta de capital fixo referente a um dado período, e a variação de estoques que nele ocorre. Em ambos os casos, esses dois conjuntos são registrados separadamente, embora eles acabem sendo expressos em termos monetários e somados como se fossem de natureza semelhante. Compóem o patrimônio de capital produzido da economia, Kp, no primeiro caso, e I, o investimento bruto - que responde pela acumulação de $\mathrm{Kp}$ - no segundo caso. $\mathrm{O}$ sistema de contas nacionais convencional ignora o capital natural, Kn, mas não é este o ponto enfatizado aqui. O que cumpre destacar é a natureza essencialmente diferente dos dois conjuntos de elementos que compreendem o capital de uma economia. E isto é feito com base em elementos da análise e Georgescu-Roegen do processo produtivo, acima esboçada.

Com base na concepção desse autor, o conjunto das máquinas, do equipamento, das construções etc. que compóem o patrimônio de capital da economia, constitui o agente produtivo 'capital fixo' da economia. Ou, na sua denominação, constitui o fundo de capital da economia. É um dos agentes de transformação no processo de produção; o que esse fundo faz no processo é fornecer serviços que, juntamente com os de outros fundos (os serviços da força de trabalho e da terra ricardiana - terra como espaço), atuam na transformação de fluxos de energia, de materiais, de componentes, em produção. Já o outro conjunto que compõe o patrimônio de capital da economia - o das matérias-primas, dos produtos intermediários, dos bens de consumo ou bens de capital produzidos, mas ainda não adquiridos por usuários finais - constitui essencialmente os estoques de materiais em processamento ou já transformados em produtos não vendidos.

Existe uma diferença fundamental entre essas duas categorias: suponhamos um dos componentes do fundo de capital fixo - digamos, uma máquina usada em um processo produção específico. Neste, a máquina presta serviços na transformação de componentes em produto; mas ao fazer isto, não se incorpora fisicamente ao produto. Havendo manutenção adequada, depois de terminada a produção este componente deixa o processo produtivo como entrou e, em uma outra jornada, voltará a prover serviços na produção. Já a outra categoria do patrimônio de capital - a das matérias-primas e componentes que são transformados pelas máquinas - ao longo do tempo seus elementos, que se originam, ou de estoques ou de outros processos produtivos, se incorporam, em parte, aos produtos e, em parte, compóem resíduos. Ao longo da realização da produção há, pois, uma transformação da natureza intrínseca desses materiais e componentes. Por isto, ao contrário do que ocorre com o componente de fundo 'máquina', os elementos transformados não estarão mais disponíveis, em outra jornada, para a produção. 
Podemos, assim, decompor o capital, Kp, em duas partes: Kps, a parcela dos fundos de serviços; e Kpe, os estoques de materiais, peças e componentes, e de mercadorias ainda não fornecidas aos usuários finais.

Uma das implicaçóes dessas duas categorias do estoque de capital é que pode ser diferente a substitutabilidade de elementos no interior de cada uma, ou entre as duas. Sabemos que os serviços do fundo Kps podem, pelo menos até certo ponto, substituir ou ser substituído pelos serviços de outros fundos (o da força de trabalho ou o da terra ricardiana). Semelhantemente, os estoques de Kpe têm componentes diferentes - por exemplo, insumos da natureza, e materiais e componentes oriundos do processo produtivo -, que também podem, pelo menos até certo ponto, substituir um ao outro na produção. Isto inclusive faz com que, como resultado de mudanças nos preços relativos de insumos materiais, tenda a ocorrer modificação na composição de Kpe. Entretanto, a substitutabilidade entre os serviços do fundo de capital, Kps, que participa do processo produtivo, e os estoques de Kpe tende, em princípio, a ser menor. Até um certo ponto ela existe, mas não é ilimitada. Isto porque a produção requer matéria e energia, juntamente com os fluxos de serviços dos agentes que as transformam. É difícil imaginar como podem ser produzidos os serviços que um automóvel fornece ao seu usuário separadamente da estrutura material do veículo. Em outras palavras, existe alguma complementaridade ente Kps e Kpe.

Do nosso ponto de vista, entretanto, assume interesse especial o exame dessa diferença entre a função de agente no processo produtivo, e a de estoque de matéria e energia do capital natural, Kn. Este também compreende a categoria - muito importante, mas que os economistas tendem a negligenciar - de fundos de serviços Kns da natureza, e a de estoques de insumos contidos na natureza, Kne. Começamos com esta última categoria.

- O estoque de insumos contidos na natureza, Kne. Os economistas costumam congregar os elementos desta categoria em dois grupos: o dos recursos naturais condicionalmente renováveis - recursos naturais que, com manejo adequado, podem ser extraídos e usados, e se renovam. E o dos recursos naturais não renováveis, aqueles cuja disponibilidade se reduz com o uso, pois não se reproduzem.

Dentre estes últimos se incluem os inventários de recursos minerais e, de forma especial, os de combustíveis fósseis. Na década de 1970 parecia que, em razão de intensa extração, os estoques do petróleo estariam com seus dias contados, e houve quem visse nas crises do petróleo um sinal de iminente limitação da expansão da economia mundial. Mas os eventos, desde então, revelam que os sinais de mercado e o progresso técnico ampliaram em muito o nosso acesso ao petróleo. Deixaram claro, também, que há a possibilidade de substituir recursos energéticos não ren- 
ováveis por formas de obtenção de energia a partir de recursos renováveis. Hoje poucos negam a possibilidade de substituição, pelo menos até certo ponto, de recursos naturais não renováveis por renováveis.

Quanto à substitutabilidade de Kne por Kp, o capital produzido, à primeira vista esta pode parecer substancial. Entretanto, é preciso ter-se em vista que o sistema econômico necessita recursos naturais para produzir bens de capital. Na verdade, há uma relação circular entre estas duas categorias: Kne é necessário para produzir Kp; e este é necessário para extrair da natureza os recursos naturais usados como insumos do processo produtivo. Existe substitutabilidade que, outra vez, é facilitada pelo progresso técnico, mas também há relaçóes de complementaridade entre as duas categorias.

- A categoria de fundos de serviços, Kns, do capital natural. Como ocorre com o fundo de capital produzido, a natureza também fornece à economia serviços essenciais. Na verdade, mais que a economia, toda a humanidade depende desses serviços. E, em condiçôes apropriadas, eles podem continuar a ser oferecidos. Para tal, é necessário que não haja ruptura na atual estabilidade longe do equilíbrio termodinâmico do ecossistema global.

Conforme ressalta Ehrlich (1989, p. 10), "ecossistemas fornecem à humanidade um conjunto absolutamente indispensável de serviços, dentre os quais se destacam a manutenção da qualidade gasosa da atmosfera, condiçôes climáticas adequadas à vida, a operação do ciclo hidrológico (fundamental para o controle de enchentes e para a provisão de água doce para a agricultura, a indústria e os domicílios), a assimilação de resíduos, a reciclagem de nutrientes essenciais à agricultura e à atividade florestal, a formação de solos, a polinização de safras, a provisão de alimentos do mar, e a manutenção de uma imensa biblioteca genética da qual a bumanidade retirou as verdadeiras bases de sua civilização."

Está claro que o comprometimento do desempenho desse complexo de serviços fundamentais prestados pela natureza pode tornar inviável, não só a produção de certos setores da economia - como, por exemplo, a agricultura -, como até a própria vida, inclusive a humana. São serviços gratuitos, mas fundamentais; muitos são insubstituíveis e, assim, infinitamente valiosos. O fato de que esses serviços vêm fluindo por si sós, dia após dia, na forma de 'dádivas gratuitas da natureza' não nos permite concluir que esses recursos naturais devem ser omitidos da análise do funcionamento do sistema econômico - embora, até recentemente, a análise econômica tenha feito isto.

A natureza desempenha, assim, funçôes essenciais e insubstituíveis; na tipologia sugerida por Georgescu-Roegen, essas funções são elementos do fundo de capital Kns; elas originam serviços essenciais para o funcionamento do sistema econômico. 
Note-se que existe alguma semelhança entre o fundo de capital natural, Kns, e o fundo de capital produzido, Kps; entretanto, essa analogia não vai muito longe. Diferentemente do que acontece com o capital produzido, o fundo de capital natural geralmente não tem dono - na verdade, nem a imaginação fértil de modelistas econômicos originou ainda sugestôes de como atribuir direitos de propriedade a parte expressiva dos componentes de Kns. Da mesma forma - ou, como ressalta Ayres (1993), por isto mesmo -, a maioria desses componentes está fora do domínio de mercados, e por mais que os economistas se esforcem, não vem sendo possível atribuir, de forma consistente, valores a esses componentes e nem definir 'preços-sombra' para os serviços por eles prestados. Além disto, não existem substitutos tecnológicos plausíveis para muitos deles.

Na verdade, ainda há enorme incerteza sobe a operação de vários dos componentes do fundo de serviços da natureza. Sabemos que, como qualquer fator de fundo, Kns também necessita de 'manutenção' da sua capacidade de prestar serviços, para evitar que ela venha a ser seriamente erodida. Não se nega que muitos dos componentes do fundo de serviços da natureza são dotados de resiliência - de capacidade de regeneração em face de impactos, tanto naturais como resultantes do funcionamento do sistema econômico. A ciência nos informa, todavia, que há limites para essa capacidade de regeneração que, se excedidos, podem desestabilizar ecossistemas e originar catástrofes. Mas o que a ciência ainda não fez de forma convincente foi fornecer detalhes concretos e insofismáveis sobre esses limites - como fica abundantemente claro da controvérsia ainda não resolvida sobre as mudanças do clima global causados pelo efeito 'estufa'.

Uma outra diferença entre o fundo de serviços do capital produzido, Kps, e o fundo de serviços do capital natural, Kns, é que se ocorrerem rupturas como as acima indicadas, pode não haver volta. No caso de muitos componentes de Kns, uma expansão descontrolada de atividade antrópica pode provocar ruptura impossível de ser corrigida. Ou seja, ocorrendo tal ruptura, ela pode ser irreversível. Conforme ressalta Ayres, (1993), a perda de espécies, a destruição de habitats, o acúmulo crescente de gases do efeito estufa, a intoxicação de solos, das águas subterrâneas, do lodo dos lagos e dos estuários por metais e químicos tóxicos não são reversíveis por nenhuma técnica que possa ser desenvolvida nas próximas décadas.

Estes são apenas alguns exemplos de possíveis rupturas irreversíveis da capacidade de geração de serviços de componentes de Kns; em muitos dos ecossistemas individuais em que isto aconteceu observaram-se passagens traumáticas de uma situação de estabilidade longe do equilíbrio a outra, sem possibilidades de volta. E há aqui uma enorme diferença em relação ao que tende a acontecer em casos de uso inadequado de um componente do fundo de capital produzido - uma máquina, por exemplo. Quando isto acontece, geralmente é possível reconstruir a máquina; o impacto gerado por um 
uso inadequado pode ser revertido. Mas isto pode não ocorrer, por exemplo, com um ecossistema que, também por uso inadequado, sofre a ruptura da desertificação.

\section{HIPÓTESES AMBIENTAIS E A CONTROVÉRSIA Sfor VERSUS Sfra}

Da discussão acima fica claro que a visão da sustentabilidade fraca, Sfra, se concentra principalmente no componente de estoque de insumos, Kne, do capital natural. Como vimos, por suas características, os insumos oriundos do capital natural exibem substitutabilidade e esta é tornada ainda maior pelo desenvolvimento tecnológico. Foi principalmente a esse tipo de componente de Kn que Solow se referiu em sua aula magna de 1973, em que praticou profissão de fé em relação à substitutabilidade entre recursos naturais e recursos produzidos. Na ocasiáo, essa ênfase do autor sobre insumos da natureza se justificava dado o pessimismo que a crise do petróleo havia infundido na opinião pública mundial, que antevia fortes obstáculos ao crescimento em razão de iminente escassez desse insumo básico. E ninguém nega hoje que esse pessimismo se mostrou exagerado. Ou seja, apenas sob o prisma do componente Kne do capital natural pode-se concordar com a visão da Sfra que hoje prevalece na economia ambiental neoclássica.

Cumpre ressaltar, entretanto, que Solow continuou a focalizar a sustentabilidade principalmente da perspectiva de Kne. No seu trabalho de 1993 - em que sumaria a visão de sustentabilidade que ajudou a construir - reconhece que existem os problemas da degradação ambiental, mas argumenta que o tratamento destes deve ser essencialmente o mesmo; ele envolve a mensuração em termos monetários do capital natural sujeito à degradação, o cálculo de preços sombra e o estabelecimento de substitutabilidades. Solow (1993, p. 171) reconhece que a degradação ambiental apresenta casos bastante complicados, não apenas pelas dificuldades de mensuração, mas porque existem aspectos insubstituíveis do meio ambiente. Mas, para o autor, trata-se de exceções à regra; considera os recursos ambientais majoritariamente como estoques, sujeito à depleção e passíveis de substituição por outros fatores de produção. ${ }^{14}$

E o outro componente - o do fundo de serviços essenciais prestados pela natureza? A visão da Sfra virtualmente o ignora; e isso se explica, basicamente, pela bipótese ambiental que serve de base a esta visão. Um exame das principais correntes de pensamento da economia do meio ambiente revela que estas adotam uma das seguintes hipóteses ambientais: a hipótese ambiental tênue, a de um meio ambiente neutro, passivo; um meio ambiente que pode incomodar se fortemente agredido, mas que é basicamente estável e, especialmente, dotado de reversibilidade. E a hipótese ambiental aprofunda-

14 Temos aqui um outro exemplo de "hábitos descuidados de pensamento", da crítica de Joan Robinson da análise neoclássica. 
da, a de um meio ambiente frágil, que pode sofrer alterações potencialmente desestabilizadoras em conseqüência de pressões antrópicas cumulativas.

A bipótese ambiental tênue, que está na base da economia ambiental neoclássica, considera que cabe a outras disciplinas - por exemplo, à ecologia - analisar detalhes dos impactos sobre o meio ambiente do funcionamento do sistema econômico, e que o economista deve concentrar sua análise de fenômenos resultantes de tal inter-relação que atingem o âmago do sistema econômico. As complicaçóes resultantes desses impactos são, assim, excluídas com hipóteses simplificadoras; hipóteses que são justificadas pela necessidade de centrar a análise em aspectos fundamentais. Argumenta-se que este é o procedimento usual na ciência.

Para formulações que se valem dessa hipótese ambiental, por exemplo, a degradação da poluição é de interesse, não pelo que possa estar ocorrendo com o meio ambiente propriamente dito (pois este é passivo e dotado de reversibilidade), mas pelo reflexo de alterações ambientais causadas pelo funcionamento da economia sobre o bem-estar dos indivíduos em sociedade. A hipótese ambiental tênue é, pois, central para abordagens apoiadas na visão da sustentabilidade fraca.

Uma razão por que o ramo da economia ambiental que emanou da análise econômica convencional se vale da hipótese ambiental tênue e enfatiza o componente de estoque de insumos da natureza, Kne, está em que sua epistemologia se choca com alguns dos atributos do fundo de serviços básicos, Kns, e especialmente com os atributos da absoluta essencialidade - ou seja, da não substitutabilidade de componentes deste fundo por outros em processos naturais de interesse da economia; e o da irreversibilidade de alguns dos impactos ambientais do funcionamento do sistema econômico. GeorgescuRoegen $(1975$, p. 348) criticou acerbamente a análise econômica convencional por sua insistência em se apoiar em uma epistemologia - ou seja, em um conjunto de princípios, hipóteses e fundamentos lógicos - mecanicista, já "banida até pela física." 15 Uma decorrência disto é que sua modelagem não se coaduna com tais atributos de Kns. De forma especial, a sua epistemologia se choca com a propriedade da irreversibilidade; a saída, portanto, é contornar o problema, lançando mão de hipóteses simplificadoras.

O atributo da absoluta essencialidade incomoda porque dificulta a atribuição de valores aos fundos de serviços ambientais que têm tal atributo e o cálculo dotado de algum sentido de preços pelos serviços de tais fundos. $\mathrm{E}$ a análise econômica convencional perde o pé sem valores e sem preços que façam algum sentido. Sem estes, que políticas

15 Para Georgescu-Roegen (1975, p. 348), a epistemologia mecanicista da análise econômica convencional a leva a considerar o processo econômico "um análogo mecánico, consistindo - como todos os análogos mecánicos de um principio de conservação e uma regra de maximização." $\mathrm{O}$ autor mostra que, ao contrário do que aconteceu com a física, a química, a biologia e a cosmologia, ramos da ciência que há muito rejeitaram a essa epistemologia, a análise econômica convencional continua a se valer dela. 
apoiadas em mecanismos de mercado sugerir em situaçôes de alto risco de danos ambientais irreversíveis? Complica, também, o fato de que, em casos de absoluta essencialidade, não existe o 'trade-off' da substitutabilidade. ${ }^{16}$ Se a expansão da economia ameaçar produzir danos irreversíveis sobre componentes do fundo de serviços naturais básicos a ponto de fazer com que seu potencial de prestação desses serviços seja irreparavelmente comprometido, essa expansão será claramente não sustentável. Sendo danificados os fundos de prestação desses serviços, eles tendem a não poder ser substituídos pelo capital produzido.

A característica da incerteza dobre o funcionamento de certos fundos de serviços básicos do capital natural também atrapalha. Solow (1993, p. 171), por exemplo, reconhece que existem profundas incertezas sobre alguns impactos ambientais acerca do funcionamento do sistema econômico; chega a indicar que estes podem nos forçar a deixar de lado preços-sombra e trabalhar com indicadores físicos. Mas não vai além disto, dando a entender que se trata de exceções à regra.

Mas será que é isso mesmo? A verdade é que ainda é elevado o nosso desconhecimento a respeito de vários dos mecanismos mediante os quais a natureza gera serviços básicos e sobre as reais conseqüências de ações que provoquem danos irreversíveis em tais fundos. Isso tem levado a sugestôes de moderação, apoiados no princípio da precaução. Se for elevada a possibilidade de impactos severos e irrecuperáveis de açóes humanas, por que não moderar ou eliminar os fatores causadores desses impactos até que se conheça melhor os mecanismos envolvidos e os riscos deles decorrentes? ${ }^{17}$

Contrastando com a postura dos proponentes da sustentabilidade fraca, as formulaçôes que se valem da hipótese ambiental aprofundada enfatizam o conjunto das relações entre o sistema econômico e o meio ambiente. Análises que se valem dessa hipótese se fazem do prisma de quem, por assim dizer, se situa na fronteira entre o sistema econômico e o meio ambiente, examinando cuidadosamente as relações entre eles. Tais análises tendem a considerar que há a possibilidade concreta do funcionamento desregrado de o sistema econômico vir a desestabilizar o ecossistema global, com impactos poten-

16 Solow (1993, p. 171) chega a admitir que alguns atributos ambientais são essenciais e não substituíveis. Mas sai pela tangente; meramente conclui que nesses casos "the calculus of trade-offs does not apply."

17 Recentemente, entretanto, o princípio da precaução está sendo usado às avessas. $\mathrm{O}$ argumento é basicamente o seguinte: existem alguns componentes do fundo de capital natural importantes para a expansão da economia, mas sobre os quais ainda há considerável incerteza. Se, de um lado, desconhecemos os danos sobre as gerações futuras associados à continuação da expansão no seu uso, e, do outro lado, forem muito altos os custos em termo de produção, renda e emprego sacrificados no presente pela contenção no seu uso, por que não continuar como vem se fazendo, até que se reduzam as incertezas e se tenha uma posição mais firme a respeito do que deve ser feito? Esta é a postura de alguns países em relação às medidas de contenção das emissões de gases do efeito estufa, preconizadas pelo Protocolo de Kioto, que objetivam evitar mudanças climáticas potencialmente catastróficas. 
ciais preocupantes sobre a sociedade humana em um futuro mais distante. ${ }^{18}$ Para essas correntes o centro de atenção também é a economia, mas elas focalizam especificamente os impactos potenciais em termos da destruição de parcelas importantes do fundo de serviços da natureza, Kns. Análises conduzidas do ponto de vista da hipótese ambiental aprofundada se afinam, pois, com a visão da sustentabilidade forte.

\section{COMENTÁRIOS CONCLUSIVOS}

Uma das constatações que se espera que este trabalho tenha permitido reafirmar é a da versatilidade e da importância da obra de Nicholas Georgescu-Roegen. Economista brilhante e filósofo da ciência meticuloso, deixou extensa - e em partes, densa - obra que ainda contém muito material a ser explorado, tanto em revisóes de aspectos da análise econômica como para servir de base à apreciação de problemas concretos.

O trabalho fez isto no contexto do debate que a economia do meio ambiente vem travando em torno do desenvolvimento sustentável. Esperamos ter conseguido mostrar que as contribuições de Georgescu-Roegen à teoria da produção oferecem importante material para enriquecer a discussão, aumentando significativamente a precisão das análises sobre as quais ela se apóia. De forma especial, a incorporação, pela economia do meio ambiente, da distinção entre capital natural de estoque e a do fundo de serviços ambientais básicos forçaria as visões sobre a sustentabilidade a se confrontarem com aspectos fundamentais da inter-relação entre o sistema econômico e o meio ambiente. O emprego de hipóteses simplificadoras extremas se tornaria mais difícil; uma estrutura conceitual explicitando esses dois componentes do capital natural acabaria revelando o absurdo de algumas das simplificações comumente feitas.

\section{REFERÊNCIAS BIBLIOGRÁFICAS}

Ayres, Robert U. Cowboys, cornucopians and long-run stability. Ecological Economics, v. 8, p. 189-207, 1993.

Boulding, Kenneth E. Equilibrium, entropy, development and autopoiesis: towards a disequilibrium economics. Eastern Economic Joumal, v. VI, n. 3-4, p. 178188, ago./out. 1980.

Cohen, Avi; Harcourt, G. C. Whatever happened do the Cambridge capital theory controversies? Journal of Economic Perspectives, v. 17, n. 1, p. 199-214, Winter 2003.

18 Para uma resenha de contribuições com base na hipótese ambiental aprofundada, ver Mueller (2001, e 2004, Parte IV). 
CMMD. World Commission on Environment and Development Our common future. Oxford: Oxford University Press, 1987.

Ehrlich, Paul. The limits to substitution: meta-resource depletion and a new economic-ecological paradigm. Ecological Economics, p. 9-16, 1989.

Faber, Malte; Manstetten, Reiner; Proops, John. Ecological economics - concepts and methods. Cheltenham, UK: Edward Elgar, 1998.

Georgescu-Roegen, Nicholas. Analytical economics, issues and problems. Cambridge, Mass.: Harvard University Press, 1967.

Process in farming versus process in manufacturing: a problem of balanced development. In: Papi, Ugo; Nunn, Charles (edit.), Economic problems of agriculture in industrial societies. Londres: Macmillan, 1969, p. 497-533.

. The entropy law and the economic process. Cambridge, Mass.: Harvard University Press, 1971.

. Energy and the economic myths. Southern Economic Journal, v. 41, n. 3, p. 347-381, 1975.

. Matter matters, too. In: Wilson, Kenneth D. (ed.), Prospects for growth changing expectations for the future. Nova Iorque: Praeger Publishers, 1977, p. 293-313.

. The entropy law and the economic process in retrospect. Eastern Economic Journal, v. XII, n. 1, p. 3-25, jan./mar. 1986.

Lélé, Sharchchandra. Sustainable development: a critical review. World Development, v. 19, n. 6, p. 607-21, 1991.

Mueller, Charles C. Economics, entropy and the long term future: conceptual foundations and the perspective of the economics of survival. Environmental Values, v. 10, p. 361-84, 2001.

. Os economistas e as inter-relações entre o sistema econômico e o meio ambiente. Versão preliminar, NEPAMA, Departamento de Economia, UnB, 2004, 306p.

Pearce, David W.; Turner, R. Kerry. Economics of natural resources and the environment. Baltimore: The Johns Hopkins University Press, 1990.

Robinson Joan. The production function and the theory of capital. Review of Economic Studies, v. 21, n. 2, p. 81-106, 1953-54.

Simonsen, Mario Henrique. Teoria microeconômica. Rio de Janeiro: Fundação Getúlio Vargas, 1971.

Solow, Robert. The economics of resources or the resources of economics. American Economic Review, v. LXIV, n. 2, p. 1-14, maio 1974.

Palestra no Marine Policy Center do Woods Hole Oceanographic Institution, Woods Hole, Massachusetts, em 14 de junho de 1991. 
An almost practical step toward sustainability. Resources Policy, v. 19, n. 3, p. 162-172, sept. 1993.

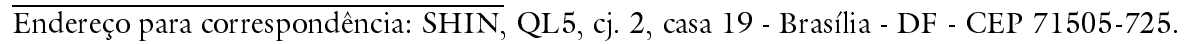

E-mail: cmueller@unb.br.

Trabalho elaborado como base à participação do autor na Mesa Redonda 2, Sustentabilidade e Crescimento Econômico, do Seminário em Honra de Nicholas Georgescu-Roegen, promovido pela Sociedade Brasileira de Economia Ecológica, São Paulo, FEA/USP, 2 e 3 de setembro de 2004.

(Recebido em outubro de 2004. Aceito para publicação em junho de 2005). 